\title{
Absorbance Unit
}

National Cancer Institute

\section{Source}

National Cancer Institute. Absorbance Unit. NCI Thesaurus. Code C73686.

A unit of optical density expressed as the absorbance of light transmitted through the medium on the logarithmic scale. 